\title{
Radiation Dose Unit
}

National Cancer Institute

\section{Source}

National Cancer Institute. Radiation Dose Unit. NCI Thesaurus. Code C18068.

A unit of measurement of the dose of radiation received or absorbed. 